\title{
FERRAMENTAS E TÉCNICAS PARA ESTIMULAR A CRIATIVIDADE NO
} AMBIENTE DE TRABALHO

\author{
Alyne Gonçalves da Silva (alynegoncalves@ yahoo.com.br) - Universidade de São Paulo \\ Msc. Renato Vizioli (renato.vizioli@gmail.com) - Universidade de São Paulo
}

\section{RESUMO}

Esse artigo tem como objetivo principal avaliar a aplicação de ferramentas e técnicas de simples implementação que visam estimular a criatividade no ambiente de trabalho, para entender de forma prática se elas fomentam o comportamento criativo dos profissionais dentro das organizações na busca pelas soluções de problemas, além disso, diferenciar os termos criatividade de inovação. No mundo globalizado, a velocidade na qual as coisas evoluem contribue para o sucesso ou fracasso dos novos produtos e serviços. As organizações buscam profissionais que consigam inovar, reduzir custos e aumentar a produtividade e para que isso aconteça, a criatividade desses profissionais é colocada em judicie rotineiramente. Cinco ferramentas e técnicas foram aplicadas na prática em uma empresa do setor de telecomunicações, para avaliar se elas estimulam a criatividade dos profissionais, proporcionando um estudo de caso que trouxe importantes conclusões a respeito da promoção da criatividade em meio ao ambiente corporativo, sendo este direcionamento, de grande importância para a área de gestão organizacional e que ainda pode servir de base fundamental ao andamento de futuras pesquisas. Sobre as conclusões desse trabalho, entende-se, por meio dos resultados que a criatividade estimulada e imposta, pela aplicação das ferramentas e técnicas organizacionais que foram revisadas, trouxe uma intensa e potencialmente maior criatividade para a busca de soluções a um problema específico e tal correlação e entendimento proporciona a compreensão do quão importante são as ferramentas e técnicas para promoção e restauração da criatividade no ambiente de trabalho.

Palavras chave: Criatividade. Técnicas de criatividade. Ferramentas de criatividade. 


\section{INTRODUÇÃO}

Olhando para traz é possível observar que muitas pessoas criativas desenvolveram soluções ou abriram caminhos por onde ninguém havia transitado. É possível que essas pessoas tivessem uma aptidão maior que outras pessoas para deixar um legado que até hoje é lembrado. Mas será que é preciso ter um talento excepcional para ser criativo? Será que a criatividade tem mais a ver com a prática do que com dom?

Com a globalização, a velocidade na qual os produtos e serviços evoluem chega a ser assustadora. Os ciclos de vida dos produtos foram reduzidos, a competitividade aumentada e cada vez mais as empresas buscam ideias que agreguem valor aos seus produtos e serviços e que podem valer milhões, como por exemplo: Uber - 65 bilhões de dólares, AirBNB - 25,5 bilhões de dólares, Snapchat - 16 bilhões de dólares (AUSTIN, CANIPE \& SLOBIN, 2015). É necessário descobrir como manter o cérebro trabalhando em busca de novas ideias para colocá-las em prática no menor tempo possível.

Wood Jr. (2004), comenta que a maioria das publicações sobre mudança organizacional, falam primeiramente a respeito da fantástica velocidade das mudanças sociais, econômicas, políticas e tecnológicas deste século, além de apontarem para a constante necessidade de adaptação que as empresas devem mostrar para fazer frente a essas mudanças.

Alencar (1996) comenta que "a competição empresarial sem precedentes que caracteriza o momento atual" é vista como "um dos fatores contribuintes para despertar a consciência das organizações para o potencial criativo de seus recursos humanos." Acrescenta que além desse fator, "as mudanças constantes no cenário global" e "as mudanças nas leis e regulamentos que afetam a vida do empresário na área internacional" também contribuem para isso. O autor comenta ainda que "um conjunto de competências torna-se necessário, sobretudo no que diz respeito à capacidade de pensar, de resolver novos problemas e implementar novas ações." Nesse contexto, as organizações [...] "estarão a exigir habilidades, destrezas, atitudes e informações que atualmente não somos capazes de antecipar".

Seguindo esse contexto, as organizações buscam profissionais cada vez mais capacitados para propor soluções inovadoras, lucrativas e que apresentem o menor custo possível. Para conseguir atingir esse mix, a criatividade dos profissionais é colocada em judicie constantemente e acaba ficando limitada, devido à rotina que enfrentam em seu dia-a-dia.

A criatividade é uma habilidade que pode ser desenvolvida e para isso, esse artigo apresenta cinco ferramentas e técnicas que podem ser inseridas no dia a dia de trabalho de quaisquer profissionais para estimular a criatividade.

\section{REFERENCIAL TEORICO}

Apresenta-se um breve relato sobre o cenário econômico atual e sobre o serviço de TV por assinatura no Brasil, intencionalmente adicionado para que seja possível entender o momento atual das empresas desse setor e porque a criatividade se faz necessária.

Atualmente o Brasil enfrenta uma crise econômica, onde enfrenta quatro grandes obstáculos, principalmente:

- A recessão: O PIB apresenta cenário de queda em 2015, previsão de retração em 2016 e nenhum crescimento em 2017, segundo o Banco Mundial e Fundo Monetário Internacional (FMI). (MERCADOSEESTRATEGIAS, 2016). 
- A inflação: Subiu para 10,67\% em 2015, alcançando o maior nível desde 2002, de acordo com os números do IBGE e Banco Mundial. (MERCADOSEESTRATEGIAS, 2016).

- A desvalorização cambial: Elevou o valor do dólar, que valia R 2,66 em janeiro/2015 para R \$ 3,98 em março/2016, conforme dados do Banco Central do Brasil. (MERCADOSEESTRATEGIAS, 2016).

- O desemprego: Que correspondia a 8\% da População Economicamente Ativa (PEA) em 2015 e subiu para 11,2\% no trimestre de fev/16 a abr/2016. (SALES, R., 2016).

O mercado de telecomunicações, mais especificamente, o mercado de TV por assinatura, enfrenta um dos piores cenários de crise da história. De 2014 para 2015 o setor perdeu meio milhão de assinantes, conforme figura 1. Isso mostra que milhares de famílias estão sendo atingidas pela crise econômica do país e deixam de priorizar o pagamento da TV por assinatura. Por esse motivo, as empresas do setor estão buscando manter os clientes satisfeitos para mantê-los em sua base e garantir o faturamento.

Figura 1. Evolução do Número de Assinantes de TV por Assinatura (mm). Fonte: ABTA, Dados do Setor (2016)

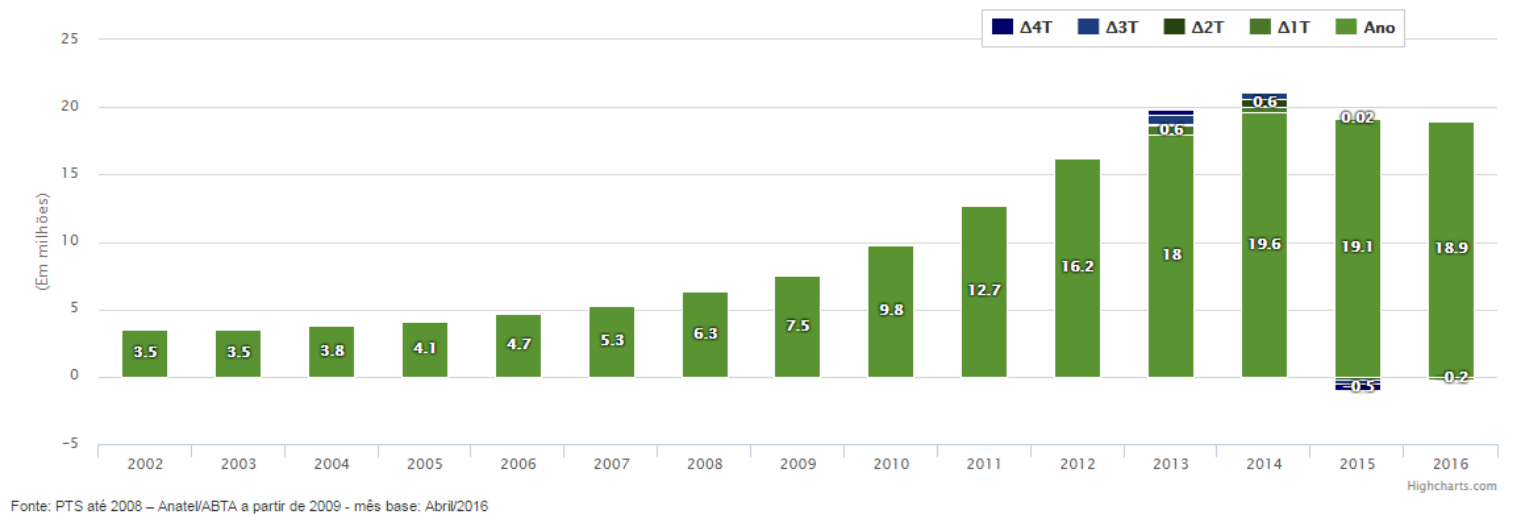

O serviço de TV por Assinatura consiste na distribuição de sinais de vídeo e/ou áudio para assinantes. De acordo com a Anatel, órgão que regulamenta o serviço de telecomunicações no Brasil, o país encerrou o mês de julho/2016 com 18,9 milhões de contratos de TV por assinatura, presente em 28,03\% dos domicílios brasileiros, conforme tabela 1. (ANATEL, 2016)

Tabela 1. Número de assinantes e densidade dos serviços de TV por Assinatura em julho de 2016, por Região. Fonte: Anatel (2016)

\begin{tabular}{|l|c|c|}
\hline \multicolumn{1}{|c|}{ Regiōes } & Assinantes & Densidade por 100 Domicílios \\
\hline Brasil & 18.927 .599 & 28,03 \\
\hline Centro-Oeste & 1.350 .963 & 26,02 \\
\hline Nordeste & 2.204 .754 & 12,4 \\
\hline Norte & 802.891 & 16 \\
\hline Sudeste & 11.704 .612 & 40,03 \\
\hline Sul & 2.864 .379 & 27,8 \\
\hline
\end{tabular}


No site da Anatel (2016), é possível conhecer os quatro tipos de tecnologias disponíveis para prestação de serviços de TV por Assinatura. A tabela 2 apresenta a participação percentual do número de acessos por tipo de tecnologia.

- $\quad$ TVC (TV a Cabo) e FTTH (Fiber to the Home) onde meios físicos são necessários (como cabos coaxiais ou fibra ótica) para distribuição dos sinais;

- MMDS (Serviço de Distribuição de Sinais Multiponto Multicanal), onde se utiliza espectro radioelétrico em micro-ondas (2500 a $2680 \mathrm{MHz}$ ) para distribuição de sinais;

- TVA (TV por Assinatura) onde se utiliza radiofrequências de um único canal na faixa de UHF para distribuição de sinais;

- DTH (Serviço de Distribuição de Sinais de Televisão e de Áudio por Assinatura Via Satélite), onde a distribuição de sinais é feita via satélite aos assinantes.

Tabela 2. Participação Percentual por Tecnologia. Fonte: Anatel (2016)

\begin{tabular}{|c|c|c|c|c|c|c|c|}
\hline Tecnologia & Janeiro/2016 & Fevereiro/2016 & Março/2016 & Abril/2016 & Maio/2016 & Junho/2016 & Julho/2016 \\
\hline DTH & $\mathbf{5 7 , 9 7 \%}$ & $\mathbf{5 7 , 7 2 \%}$ & $\mathbf{5 7 , 5 4 \%}$ & $\mathbf{5 7 , 4 2 \%}$ & $\mathbf{5 7 , 3 5 \%}$ & $\mathbf{5 7 , 3 1 \%}$ & $\mathbf{5 7 , 4 1 \%}$ \\
\hline FTH & $\mathbf{0 , 9 1 \%}$ & $0,93 \%$ & $0,94 \%$ & $0,96 \%$ & $0,99 \%$ & $1,02 \%$ & $1,06 \%$ \\
\hline MMDS & $0,05 \%$ & $0,05 \%$ & $0,05 \%$ & $0,05 \%$ & $0,04 \%$ & $0,04 \%$ & $0,04 \%$ \\
\hline TVA & $0,02 \%$ & $0,02 \%$ & $0,02 \%$ & $0,02 \%$ & $0,02 \%$ & $0,01 \%$ & $0,00 \%$ \\
\hline TVC & $41,06 \%$ & $41,29 \%$ & $41,46 \%$ & $41,56 \%$ & $41,60 \%$ & $41,61 \%$ & $41,49 \%$ \\
\hline Total & $100 \%$ & $100 \%$ & $100 \%$ & $100 \%$ & $100 \%$ & $100 \%$ & $100 \%$ \\
\hline
\end{tabular}

Como há muitas opções disponíveis, os clientes podem escolher qual operadora desejam assinar. Por isso, as empresas se preocupam em manter uma grade de canais atrativa, garantir a qualidade da imagem e um bom relacionamento com seus assinantes. Como a concorrência e a crise afetam o setor é preciso buscar soluções criativas para manter-se competitivo e atuante nesse mercado.

\section{CRIATIVIDADE}

Bruno-Faria, Veiga e Macêdo (2008), constataram após revisar as principais obras produzidas entre 1997 e 2006, que existem mais de 100 definições para o termo criatividade na literatura científica desde 1950, mas que não há grandes divergências de sentido entre essas definições.

Neste capítulo, apresenta-se a proposta de alguns autores acerca da definição do termo criatividade, bem como a sua diferenciação do termo inovação, além de cinco ferramentas e técnicas que estimulam a criatividade.

\subsection{Conceitos de criatividade}

A palavra criatividade tem origem no latim creare, que significa criar e pode ser classificada de diversas formas, como: a capacidade de criar, produzir ou inventar coisas novas, transformar situações e inovar no modo de agir. (SIGNIFICADOBR, 2016).

Alencar (1996) menciona que o ato de criar está interligado com "insights", invenções, intuição, iluminação e originalidade, ele conceitua criatividade como "o processo que resulta na emergência de um novo produto (bem ou serviço), aceito como útil, satisfatório e/ou de 
valor por um número significativo de pessoas em algum ponto no tempo" (ALENCAR, 1996).

Correia (2004, apud CORREIA \& DELLAGNELO, 2004) conceitua criatividade como sendo o processo complexo em que elementos relativos à personalidade e ao ambiente interajam para que um novo produto surja e em algum momento seja aceito por um grupo de pessoas.

Livingstone, Debra e Barr (1997, apud BEDANI, 2008) definem criatividade como a geração de ideias e produtos (novos e úteis), que resultam do ajuste entre os fatores individuais e organizacionais.

Sternberg e Lubart (1999, apud FONSECA \& BASTOS, 2003) conceituam criatividade como a habilidade de produzir algo original, útil, que possa sofrer adaptação frente às dificuldades das tarefas.

\subsection{Diferenciação de criatividade e inovação}

Alencar (1996) conceitua inovação como sendo à aplicação concreta de uma nova ideia, enquanto a criatividade é apenas o elemento conceitual desta.

Shalley e Perry-Smith (2008) dizem que criatividade é necessária, mas não suficiente para se obter inovação. Para esses pesquisadores, as ideias criativas são precursoras da inovação e representam a base que favorece o surgimento da inovação.

De acordo com Chen (2006) "a criatividade refere-se a novos produtos socialmente valorizados no domínio estudado, e, inovação, é o processo de transformar uma invenção ou uma ideia em ação que é comercialmente útil e valioso".

\subsection{Ferramentas e técnicas que estimulam a criatividade}

Existem muitas ferramentas e técnicas que estimulam a criatividade, contudo, serão consideradas cinco delas para realizar o estudo de caso e comparar os resultados. Nesse subitem há uma breve definição sobre cada uma delas:

\subsubsection{Brainstorm}

Osborn (1953) inventou o "Brainstorm", que é uma ferramenta de criatividade utilizada para gerar novas ideias num ambiente livre de críticas e restrições. Essa ferramenta é dividida em duas etapas, a primeira caracterizada pela geração de muitas ideias sem crítica e a segunda, na qual se critica as ideias geradas na etapa anterior para escolher a melhor delas. É uma ferramenta muito utilizada quando se precisa gerar muitas ideias em um curto prazo sobre um problema ou tema específico que precisa ser solucionado.

Cross (2008, apud VIZIOLI, 2016), diz que brainstorm deve ser composto por um grupo pequeno, entre 4 e 8 pessoas, com perfis distintos, especialistas e não especialistas na área, sem hierarquia. Esse grupo normalmente inicia a discussão com a pergunta: "Como podemos melhorar ou fazer tal atividade?", em uma sessão que dura cerca de 20 a 30 minutos, onde os participantes expõem suas ideias num momento onde não é permitido críticas ou aversões, posteriormente classificam e hierarquizam essas ideias de acordo com os critérios que foram estabelecidos pelo grupo, escolhendo então a solução que melhor atender aos requisitos. 


\subsubsection{Brainwriting}

Reis (2008) informa que o brainwriting é uma técnica muito similar ao brainstorm, contudo, as ideias são anotadas em pedaços de papel ao invés de serem apresentadas oralmente. Para o autor, a dinâmica dessa ferramenta permite que todos os participantes tenham ideias simultaneamente além de incentivar o desenvolvimento das ideias geradas por outros participantes. De acordo com o autor, as principais etapas dessas dinâmicas consistem em informar de forma clara aos participantes qual o problema a ser resolvido, os participantes terão 5 minutos para escrever suas ideias para solução no papel, individualmente e sem se identificar. Após esse tempo, passam a folha ao participante ao seu lado que terá mais cinco minutos para acrescentar suas próprias ideias, isso pode se repetir por diversas vezes, mas em geral, três rodadas são suficientes. Na sequência o facilitador recolhe os papéis e escreve as ideias para expô-las nas paredes do ambiente ou uma das pessoas do grupo lê todos os papéis em voz alta e por fim, discutem as ideias expostas, descartando as impraticáveis e selecionando as melhores para a solução. Uma das vantagens apontadas pelo autor é que pessoas mais tímidas podem participar de maneira ativa, já que não há exposição.

Baxter (2000), diz que no brainwritining todos devem escrever as suas ideias de forma sucinta, em post-its ou cartões pequenos, sem mostrá-las a nenhum outro participante, seguindo assim até que as ideias se esgotem. Após, discutem as ideias geradas para selecionar as melhores entre elas.

\subsubsection{Scamper}

Eberle (1996) elaborou a ferramenta de criatividade Scamper para gerar ideias em grupo. A dinâmica consiste em utilizar uma lista de palavras, mais precisamente, um conjunto de 7 verbos operadores, que permitem explorar modos diferentes de modificar um objeto, um processo, um sistema ou um serviço. As iniciais desses verbos em inglês definem o nome dessa ferramenta, que traduzindo seria: Substituir, Combinar, Adaptar, Modificar, Buscar outros usos, Eliminar e Reordenar. Segundo o autor, a utilização desses verbos estimula formas de pensar convergentes e divergentes, utilizando-os de forma inquisitiva, o que potencializa a produção de um número significativo de ideias criativas, estimula a realização de ações a partir de uma ideia básica e gera novas ideias.

\subsubsection{Seis chapéus}

Bono (1986) idealizou essa ferramenta para facilitar a produção do pensamento lateral, análise e solução de problemas sob diferentes pontos de vista ou perspectivas. Esse processo organiza o pensamento para lidar com um assunto de cada vez, diminuindo assim a sua complexidade. Pode ser realizado individualmente ou em grupo. O método dos seis chapéus permite pensar sobre um assunto a partir de seis diferentes ângulos, pois cada um dos seis chapéus tem cores diferentes que representam uma função, para estimular diferentes maneiras de pensar.

Primeiro, o chapéu branco, tem a função de pensar sobre os fatos de maneira racional, neutra e objetiva. O chapéu vermelho, tem a função de utilizar uma perspectiva emocional sobre o fato. O chapéu preto, tem a função de pensar de maneira negativa sobre o mesmo fato, buscando sempre responder a pergunta: "Por que não podemos fazer isto?". O chapéu amarelo tem a função de estimular pensamentos otimistas e esperançosos. $\mathrm{O}$ chapéu verde, tem a função de pensar de maneira criativa para gerar novas ideias. Por fim, o chapéu azul, que tem a função de controlar e organizar o pensamento, ficando responsável pelos demais chapéus. 
Os chapéus citados pelo autor têm sentido figurado, não existindo fisicamente. Segundo o autor, a dinâmica consiste em colocar um dos chapéus (simbolicamente) e desempenhar o papel definido por ele. Quando trocar o chapéu, você troca de papel e assim segue com os seis chapéus. Quando o grupo não tem conhecimento desse método, recomenda-se colocar no centro da mesa um cartaz indicando as cores e seus significados, pois durante a dinâmica, os chapéus são chamados pelas suas cores e nunca pelas suas funções.

Bono (1986) define que esse é um método funcional que estimula os participantes a mudarem seus padrões levando a formas de pensar divergentes, pois cada um dos participantes pode ser negativo em um momento, positivo em outro, pode ser racional e assim por diante. Para o autor, isso potencializa a produção de muitas ideias.

\subsubsection{Mapas mentais}

Buzan e Buzan (2010) apresenta mapas mentais como uma técnica sistematizada com foco na gestão de informação e de conhecimento, que estimula formas convergentes e divergentes de pensar, através da lógica e imagens, o que potencializa a produção de poucas ideias criativas, contudo, de qualidade.

Segundo os autores, essa técnica consiste na elaboração de um diagrama com várias conexões vinculadas a um conceito central. Esse diagrama é utilizado para expor diferentes informações sobre o tema central, de acordo com a importância dos conceitos, que são organizados em grupos, árvores, ramas ou áreas utilizadas para representar palavras, ideias, tarefas ou outros elementos conceituais que são dispostos intuitivamente.

Buzan e Buzan (2006, apud VIZIOLI, 2016), cita que mapas mentais "são representações gráficas em forma de diagrama radial, expandindo-se a partir de um conceito central que se relaciona semanticamente com outros conceitos, também hierarquicamente".

\section{METODOLOGIA E TÉCNICAS DE PESQUISA}

A metodologia é fundamental para garantir que o trabalho seja válido, trazendo problemas, hipóteses e objetivos factíveis, pertinentes e adequados ao estado da questão em que se encontra o problema.

Yin (2005p. 32) diz que "o estudo de caso é uma investigação empírica que investiga um fenômeno contemporâneo dentro de seu contexto da vida real", sendo uma investigação empírica, um método que abrange tudo - planejamento, técnicas de coleta de dados e análise dos mesmos, única e múltipla. Assim, devido à natureza da proposta que por ora se apresenta, recorrer-se-á metodologicamente ao estudo de caso e à revisão bibliográfica.

O estudo de caso foi realizado numa empresa do segmento de telecomunicações, que atua com o serviço de TV por assinatura via satélite pelo sistema digital DTH (Direct to Home), que está há mais de 18 anos no mercado. Essa empresa realiza transmissão para todo o território nacional e representa aproximadamente $30 \%$ dos assinantes de TV paga do País.

\subsection{Definição do problema}

Considerando o cenário atual, onde a crise econômica e a concorrência afetam o setor de telecomunicações, esta empresa lançou em 2015 um projeto interno que envolve mais de 160 
profissionais de áreas e formações distintas, para encontrar soluções criativas e disruptivas para problemas internos e externos que afetam seus clientes, com a finalidade de garantir a qualidade na prestação de serviços, deixando-os mais satisfeitos e evitando que deixem o serviço. Esses profissionais foram divididos em oito grupos distintos que se reúnem diariamente para identificar os problemas e criar planos de ações de curto prazo para execução, logo, a criatividade dos profissionais envolvidos é exigida todos os dias.

O problema foco desse trabalho surgiu para apoiar um cenário onde essa empresa apresenta ineficiência, relacionado ao atendimento das solicitações de controles remotos realizadas pelos seus clientes. De cada 100 controles remotos solicitados em dezembro/2015, a empresa não conseguia realizar a entrega de 37 . Em outubro/2016 após implantação de diversas melhorias nessa operação o indicador melhorou, contudo, ainda não consegue realizar a entrega de 15 controles remotos a cada 100 solicitações. O principal motivo mapeado que acarreta a não entrega do controle remoto está relacionado a inconsistências no endereço do cliente. Além da dificuldade para elevar o volume de entregas, tem-se que garantir que essa entrega aconteça dentro do prazo acordado com o cliente. E dezembro/2015 apenas 54\% das entregas ocorria dentro do prazo acordado com o cliente, e, após a implantação de muitas melhorias no processo, esse indicador atingiu $94 \%$ em outubro/2016. Contudo, a meta estipulada prevê que esse índice supere $99 \%$.

Para um dos oito grupos de trabalho, com 20 profissionais, foi apresentado esse problema e inseridas as cinco ferramentas e técnicas. Cada uma delas foi utilizada por um subgrupo composto por quatro profissionais que buscavam responder a pergunta: "Especificamente quais ações podem ser trabalhadas para solucionar os problemas de inconsistência de endereço, que impactam o não recebimento do controle remoto solicitado pelo cliente, dentro do prazo acordado?".

\section{RESULTADOS E CONCLUSÕES}

Analisando os resultado é importante perceber que a diferenciação entre ferramentas e técnicas apresentadas está na quantidade de ideias produzidas e ideias válidas. Os resultados apresentados na tabela 3 demonstram que a técnica dos seis chapéus foi a potencialmente melhor em quantidade, com 40 ideias, em contrapartida, com 55\% de ideias válidas. Já o brainstorming foi potencialmente melhor em ideias válidas com $79 \%$, seguido pelo brainwriting e mapas mentais com $78 \%$.

Tabela 3: Quantidade de Ideias por Ferramenta/Técnica Aplicada

\begin{tabular}{|c|c|c|c|c|c|c|}
\hline & & \multicolumn{5}{|c|}{ Problema 1: Endereço não localizado } \\
\hline & TOTAL & Brainstorming & Brainwriting & Scamper & Seis Chapéus & Mapas Mentais \\
\hline Quantidade de Ideias & 137 & 33 & 27 & 28 & 40 & 9 \\
\hline Quantidade de Ideias Válidas & 94 & 26 & 21 & 18 & 22 & 7 \\
\hline \% Ideias Válidas & $69 \%$ & $79 \%$ & $78 \%$ & $64 \%$ & $55 \%$ & $78 \%$ \\
\hline
\end{tabular}

Realizando uma avaliação horizontal tem-se a criação de 137 ideias, onde após descartar as ideias repetidas ou inviáveis em cada um dos subgrupos, esse número foi reduzido para 94. Contudo, ao criar uma lista única com todas as ideias válidas de todos os subgrupos, identificou-se um grande volume de ideias similares (o que é compreensível, pois as ferramentas foram aplicadas para solucionar um único problema), assim sendo, chega-se ao 
resultado de 36 ideias válidas sem nenhum caráter ou percepção de ambiguidade ou duplicidade entre todos os subgrupos, conforme pode ser observado na tabela 4.

Tabela 4: Resumo dos Resultados Obtidos

\begin{tabular}{|ccc|}
\cline { 2 - 3 } Quantidade de Ideias & \multicolumn{2}{c|}{ TOTAL } \\
\hline Quantidade de Ideias Válidas & 137 & $100 \%$ \\
Ideias Únicas (sem duplicidade entre os subgrupos) & 94 & $69 \%$ \\
\hline
\end{tabular}

Cabe destacar que todas as ideias válidas buscavam solucionar o problema apresentado e podem ser aplicáveis e fortemente viáveis. Incluíram mas não se limitaram a correção prévia das informações do endereço e disponibilização de retirada em novos canais, como site, credenciados ou canais de varejo, além disso, surgiram ideias voltadas para evitar o envio do controle remoto, como disponibilizar as funções via aplicativo ou tentativa de recuperá-lo.

Entende-se, por meio dos resultados que aqui foram desenvolvidos que a criatividade estimulada e imposta, pela aplicação das ferramentas e técnicas revisadas, trouxe uma intensa e potencialmente maior criatividade para a busca de soluções a um problema específico, o que proporciona a compreensão do quão importante elas são para promoção da criatividade.

Destarte, compreende-se a profunda necessidade, intraorganizacional, de observar a potencialidade de seus colaboradores ao desenvolvimento de ideias e soluções de caráter criativo. Todas as ferramentas e técnicas utilizadas foram potencialmente restauradoras da criatividade para os problemas organizacionais e proporcionaram um estudo de caso que trouxe conclusões a respeito da promoção da criatividade no ambiente corporativo, sendo este direcionamento, de grande importância para a área de gestão organizacional, e, ainda pode servir de base fundamental ao andamento de futuras pesquisas.

\section{REFERÊNCIAS BIBLIOGRAFICAS}

ALENCAR, E. M. L. S. de. A gerência da criatividade: abrindo as janelas para a criatividade pessoal e nas organizações. São Paulo: Makron Books, 1996.

BAXTER, M. R. Projeto de Produto: Guia Prático Para o Design de Novos Produtos. 2 ed., São Paulo, Ed. Edgard Blücher, 2000.

BEDANI, M. (2008). Valores, práticas e criatividade organizacionais: estudo do perfil cultural de uma instituição bancária. Tese de Doutorado. Programa de Pós-graduação em Psicologia social, do trabalho e das organizações. Universidade de Brasília, Brasília.

BONO, E. El pensamiento lateral, Ed. Sayrols, México, 1986.

BRUNO-FARIA, M. F.; Veiga, H. M. S. \& Macêdo, L. F. (2008). Criatividade nas organizações. rPOT, 8(1), 142-163.

BUZAN, T.; BUZAN, B. The Mind Map Book: Unlock Your Creativity, Boost Your Memory, Change Your Life. Trans-atlantic publications: New York. p. 217. 2010.

CHEN, M. H. Understanding the benefits and detriments of conflict on team creativy process. Creativity and Innovation Management. v.15, n.1, 2006. 
CORREIA, G. S. \& DELLAGNELO, E. H. L. (2004). Avaliação do potencial da estrutura para o desenvolvimento da criatividade em uma Indústria Cerâmica Catarinense. Anais XXVII EnANPAD, Curitiba - PR.

EBERLE, B. Scamper on: Games for Imagination Development. New York: Prufrock Press Inc, 1996.

FONSECA, C. A. M. \& Bastos, A. V. B. (2003). Criatividade e Comprometimento Organizacional: suas relações com a percepção de desempenho no trabalho. rPOT, 3(1), 61-88.

OSBORN, A. Applied Imagination: The Principles and Procedures of Creative Thinking. New York, New York. Ed: Charles Scribner's Sons, 1953.

REIS, D. R. Gestão da Inovação Tecnológica. Barueri, São Paulo: Manole, 2008, 206 p.

SHALLEY, C. E.; PERRY-SMITH, J. E. The emergence of team creative cognition: the role of diverse outside ties, sociocognitive network, centraility, and team evolution. Strategic Entrepreneurship Journal. p.23-41, 2008.

VIZIOLI, R. Integração da Engenharia do valor e do "Design Thinking" no processo de desenvolvimento de produtos. Qualificação para Doutorado. Pós-Graduação em Engenharia Mecânica. Universidade de São Paulo, São Paulo: USP, 2016.

WOOD JR., T. Mudança Organizacional: uma introdução ao tema. In: WOOD JR., T.

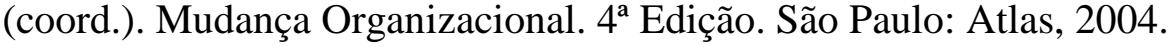

YIN. R. K. Estudo de caso: planejamento e métodos. 3 ed. Porto Alegre: Bookman,2005.

\section{Links de internet}

ABTA, DADOS DO SETOR. Disponível em: http://www.abta.org.br/dados_do_setor.asp. Acessado em 04/09/2016.

ANATEL, TV POR ASSINATURA. Disponível em: http://www.anatel.gov.br/institucional/component/content/article?id=1294. Acessado em 04/09/2016.

AUSTIN, S., Canipe, C. \& Slobin, S. The Wall Street Journal: The Billion Dollar Startup Club. Companies valued at $\$ 1$ billion or more by venture-capital firms. Disponível em: http://graphics.wsj.com/billion-dollar-club/. Publicado em 18/02/2015.

MERCADOS E ESTRATÉGIAS, BRASIL: O CENÁRIO ECONOMICO ATUAL. Disponível em: http://www.mercadoseestrategias.com/news/brasil-o-cenario-economicoatual/ Publicado em 02/03/2016. Acessado em 04/09/2016.

SALES, R. Taxa de Desemprego sobe para 11,2\% no trimestre até abril, nota IBGE. Valor Econômico. Disponível em: http://www.valor.com.br/brasil/4582235/taxa-de-desempregosobe-para-112-no-trimestre-ate-abril-nota-ibge Publicado em 31/05/2016. Acessado em 04/09/2016.

SIGNIFICADOSBR. Disponível em https://www.significadosbr.com.br/criatividade. Acessado em 29/08/2016. 